\title{
The emission of harmful compounds from the marine diesel engine fueled by a blend of $n$-butanol and marine fuel
}

ARTICLE INFO

Received: 14 July 2021

Revised: 6 August 2021

Accepted: 8 September 2021

Available online: 13 September 2021
The use of renewable fuels may be an action leading to the reduction of pollutant emissions. This group includes biobutanol as a product of biomass fermentation. Some of its physicochemical properties, including the ability to mix with hydrocarbon fuels, make it suitable for use as a fuel component for marine diesel engines. The article presents the results of research on the concentration of exhaust gas components of a Sulzer 6AL20/24 diesel engine powered by a mixture of n-butane and diesel oil. The emission intensity were calculated for the tested components: carbon monoxide, carbon dioxide and nitrogen oxides. The emission intensity surface graphs were created based on the calculated data. The tests were carried out using different concentrations of the mixture of $n$-butanol and marine fuel.

Key words: emission, marine diesel engine, $n$-butanol, marine fuel blend

This is an open access article under the CC BY license (http://creativecommons.org/licenses/BY/4.0/)

\section{Introduction}

It is estimated that almost $70 \%$ of global emissions of harmful compounds from maritime transport fall within 400 $\mathrm{km}$ from land, and have a significant impact on air quality in the coastal zone [1]. The increase in the traffic of commercial ships going to ports, not only the largest but also medium and small ones, causes a significant deterioration of air quality in coastal areas, and thus affects human health and the ecosystem. In recent virtual meeting, the International Maritime Organization (IMO) working group agreed on a set of draft guidelines to support mandatory measures to reduce the emissions of all ships [2]. The MEPC Marine Environment Protection Committee (MEPC 76) has adopted amendments to Annex VI to the International Convention for the Prevention of Pollution from Ships (MARPOL), which will require ships to reduce greenhouse gas emissions (GHG). These changes combine technical and operational approaches to improve the energy efficiency of ships, in line with the targets set in the IMO's initial 2018 GHG reduction strategy, and are important building blocks for future GHG reduction measures. The new measures will require all ships to calculate the Efficiency Existing Ship Index (EEXI) of existing ships in line with technical measures to improve their energy efficiency and establish an annual operational carbon intensity indicator (CII) and assess CII. The intensity of carbon dioxide emissions links greenhouse gas emissions with the transport work of ships. The changes apply to ships of 5000 gross tonnage and above (ships already subject to the ship fuel consumption data collecting system requirement). These ships are required to define the required annual operational carbon dioxide intensity (CII). Ships will receive an assessment of their energy efficiency $(\mathrm{A}, \mathrm{B}, \mathrm{C}, \mathrm{D}, \mathrm{E}-$ where $\mathrm{A}$ is the best), which will be included in their mandatory Administration Compliance Statement. Administrations, port authorities and other stakeholders, as appropriate, are also encouraged to provide incentives to A or B rated ships. The key decision was the establishment of reduction factors for the CII.
With 2019 as the base year for the reference lines, the reduction factor defines the mid-point of the $\mathrm{C}$-rating band for each year. The CII reduction rates were set to increase by 1 percentage point (pp) per year for 2020-2022, followed by 2 pp per year for 2023-2026. The rates for 20272030 will be decided as part of the review to be concluded by 1 January 2026. The reduction factors are as follows [3].

Table 1. Reduction factors [3]

\begin{tabular}{|c|c|}
\hline Year & Reduction from 2019 reference \\
\hline 2023 & $5 \%$ \\
\hline 2024 & $7 \%$ \\
\hline 2025 & $9 \%$ \\
\hline 2026 & $11 \%$ \\
\hline $2027-2030$ & To be decided \\
\hline
\end{tabular}

The ban will cover the use and carriage for use as fuel of oils with a density at $15^{\circ} \mathrm{C}$ higher than $900 \mathrm{~kg} / \mathrm{m}^{3}$ or a kinematic viscosity at $50^{\circ} \mathrm{C}$ higher than $180 \mathrm{~mm}^{2} / \mathrm{s}$. Ships involved in ship safety or in search and rescue, and ships involved in oil spill preparation and response would be exempted. Ships that meet certain design standards with regard to the protection of fuel tanks will have to comply with the requirements on or after 1 July 2029 [2].

Firstly efforts are made to develop more and more perfect technologies to reduce pollutant emissions. Secondly new energy sources are sought, including fuels from renewable sources. This group includes biobutanol as a product of biomass fermentation $[4,5]$.

The authors of the paper [6] examined he effects made by using various n-butanol-diesel fuel blends on the combustion history, engine performance and exhaust emissions of a turbocharged four-stroke, four-cylinder, CRDI 1154HP $(85 \mathrm{~kW})$ diesel engine. At first, load characteristics were taken when running an engine with normal diesel fuel (DF) to have 'baseline' parameters at the two ranges of speed of 1800 and $2500 \mathrm{rpm}$. Analysis of the changes occurred in the ignition delay, combustion history, the cycle-to-cycle varia- 
The emission of harmful compounds from the marine diesel engine...

tion, engine efficiency, smoke, and exhaust emissions nitrogen oxides $\left(\mathrm{NO}_{\mathrm{x}}\right)$, carbon monoxide $(\mathrm{CO})$ obtained with purposely designed fuel blends was performed on comparative bases with the corresponding values measured with 'baseline' diesel fuel to reveal the potential developing trends.

In reference [7], the authors presented bio-butanol as a renewable, environmentally friendly, and economical alternative fuel that, like many other alternative fuels such as methanol, ethanol, and natural gas, is also considered to be one of the most advantageous fuels to replacement for conventional petroleum fuels (such as gasoline or diesel fuel). Bio-butanol fuel has recently been used as an alternative fuel to conventional fuels for IC engines (gasoline or diesel engines) to meet some environmental and economic considerations. Compared with conventional fuels (gasoline and diesel fuels), bio-butanol has many advantages, so it has the potential to reduce vehicle emissions, thereby improving the atmospheric environment, reducing energy demand pressure, and significantly decreasing the car's dependence on non-renewable resource.

The research works are underway with the use of fuel blends in combustion engines and includes research on engine design also. In the paper [8], dynamic flow rates of a common rail injector using diesel fuel and different biofuels were determined. As biofuels, fatty acid methyl esters originating from canola, poultry, cattle and used cooking oil were tested. The tested fuels exhibited different physical properties e.g. density and viscosity.

In reference [9], the authors presented an experimental investigation of the relationship between the pulse width of a gasoline engine port fuel injector and the quantity of the fuel injected when butanol is used as a fuel. Two isomers of butanol, n-butanol and isobutanol, are considered as potential candidates for renewable, locally produced fuels capable of serving as a drop-in replacement fuel for gasoline, as an alternative to ethanol which poses material compatibility and other drawbacks.

\section{Research object}

The tests were carried out on the laboratory stand of the Cegielski-Sulzer 6AL20/24 marine diesel engine located in the Laboratory of Operating Marine Power Plants of the Mechanical and Electrical Faculty of the Naval Academy in Gdynia. The laboratory stand is presented in Fig. 1 and the technical data are shown in Table 2.

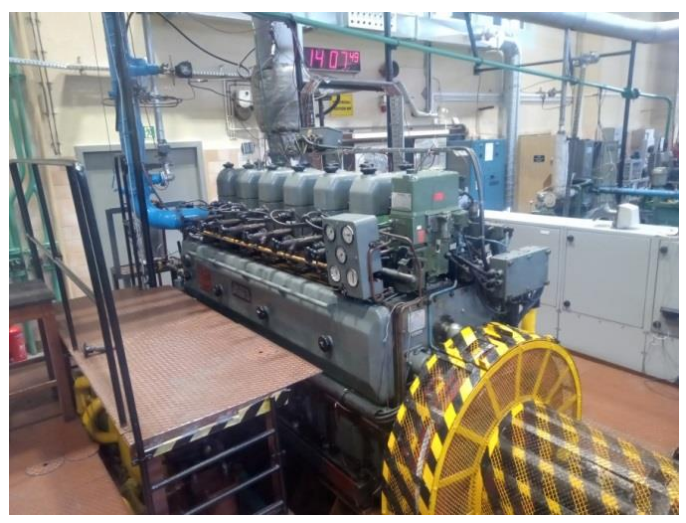

Fig. 1. The marine diesel engine laboratory stand
The Testo 350 Maritime portable exhaust gas analyzer was used to measure the concentrations of harmful compounds in the laboratory stand. The analyzer is designed to measure gas concentrations:

- oxygen $\left(\mathrm{O}_{2}\right)$,

- carbon monoxides (CO),

- carbon dioxide $\left(\mathrm{CO}_{2}\right)$,

- nitrogen oxides (NOx),

- sulfur dioxide (SO).

The device can be used as a stand-alone measuring system or part of the system. The tested marine diesel fuel (MDF) is a sulfur-free fuel, therefore sulfur oxide were not included in the conducted research.

Table 2. Marine diesel engine Sulzer type 6AL20/24

\begin{tabular}{|l|c|}
\hline \multicolumn{2}{|c|}{ Specification } \\
\hline Piston arrangement & Inline \\
\hline Cylinder diameter & $200 \mathrm{~mm}$ \\
\hline Piston stroke & $240 \mathrm{~mm}$ \\
\hline Displacement volume & 1 cyl. $-7.54 \mathrm{dm}^{3}$ \\
\hline Nominal power & $420 \mathrm{~kW}$ \\
\hline Starter & pressure compressed air $-3 \mathrm{MPa}$ \\
\hline Number of cylinders & 6 \\
\hline Number of valves per cylinder & 4 \\
\hline
\end{tabular}

According to the theory of experiment planning, one of the most important task is to determine the set of quantities characterizing the research object in terms of the investigation problem. Based on analysis, a qualitative simulation model of the object was developed. The following simplifications were adopted in the planned experiment:

A set of constant values, due to their invariable influence on the output values, are not considered;

The set of disturbing quantities are ignored due to the research conducted in similar environmental conditions;

The set of input quantities $\mathrm{x}$ are limited to the following: torque $-\mathrm{T}$, engine speed $-\mathrm{n}$, butnol concentration in the fuel $-\mathrm{C}_{\text {but }}$;

The set of output quantities are limited to: concentration of carbon monoxide in the exhaust manifold $\left(\mathrm{C}_{\mathrm{CO}}\right)$, concentration of nitrogen oxides in the exhaust manifold $\left(\mathrm{C}_{\mathrm{NOx}}\right)$, concentration of carbon dioxide in the exhaust manifold $\left(\mathrm{C}_{\mathrm{CO} 2}\right)$, oxygen concentration in the exhaust gas $\left(\mathrm{C}_{\mathrm{O} 2}\right)$.

Based on the theory of the working process and curves of characteristics, it can be assumed that the diesel engine is a non-linear object due to the exhaust gas emission. The nonlinear nature of the object, described by a function in the form of a nonlinear polynomial, is best reflected by plans with at least three input values. It is assumed that at least in model three output values are taking into account to calculate the linear and quadratic effects for them and the interactions between them. These plans were developed by Draper and Box-Behnken, compiled by Connor and Zelen [10], relatively simple $3^{* *}(\mathrm{k}-\mathrm{p})$ three-valued fractional designs and their variation - fractional designs for two- and three-valued quantities. The analysis of the poliselection plans shows that in the assumed experiment it is possible to apply a complete $3^{* *}(3-0)$ three-valued poliselection plan consisting of 1 block and 27 measurement points, which meets the requirements in terms of its feasibility and with 
acceptable efficiency. Adopting one measuring block in the layout of the plan is associated with the adopted assumption that the tests are carried out under almost unchanged environmental conditions. This assumption excludes the need to eliminate the impact of changes in test conditions as quantities corresponding to higher-order coefficients. Their impact is considered to be negligible, and there is no need to statistically assess the significance of this impact [10].

The complete three-valued plan was selected for the experiment, consisting of 1 block and 27 measuring points (Table 3). The selection of one measuring block was associated with the assumption that the tests were carried out under almost unchanged environmental conditions.

Table 3. The configurations of parameters and concentration applied in the experiment

\begin{tabular}{|c|c|c|c|}
\hline $\begin{array}{l}\text { The config. } \\
\text { number }\end{array}$ & $\begin{array}{c}\text { The engine speed } \\
n[\mathrm{rpm}]\end{array}$ & $\begin{array}{c}\text { The water break } \\
\text { torque } \\
\mathrm{T}[\mathrm{kN} \cdot \mathrm{m}]\end{array}$ & $\begin{array}{c}\text { The conc. } \\
\text { of } n \text {-butanol } \\
C_{\text {but }}[\%]\end{array}$ \\
\hline 1 & 600 & 0.98 & 0 \\
\hline 2 & 600 & 0.98 & 15 \\
\hline 3 & 600 & 0.98 & 30 \\
\hline 4 & 600 & 2.81 & 0 \\
\hline 5 & 600 & 2.81 & 15 \\
\hline 6 & 600 & 2.81 & 30 \\
\hline 7 & 600 & 4.65 & 0 \\
\hline 8 & 600 & 4.65 & 15 \\
\hline 9 & 600 & 4.65 & 30 \\
\hline 10 & 675 & 0.98 & 0 \\
\hline 11 & 675 & 0.98 & 15 \\
\hline 12 & 675 & 0.98 & 30 \\
\hline 13 & 675 & 2.81 & 0 \\
\hline 14 & 675 & 2.81 & 15 \\
\hline 15 & 675 & 2.81 & 30 \\
\hline 16 & 675 & 4.65 & 0 \\
\hline 17 & 675 & 4.65 & 15 \\
\hline 18 & 675 & 4.65 & 30 \\
\hline 19 & 750 & 0.98 & 0 \\
\hline 20 & 750 & 0.98 & 15 \\
\hline 21 & 750 & 0.98 & 30 \\
\hline 22 & 750 & 2.81 & 0 \\
\hline 23 & 750 & 2.81 & 15 \\
\hline 24 & 750 & 2.81 & 30 \\
\hline 25 & 750 & 4.65 & 0 \\
\hline 26 & 750 & 4.65 & 15 \\
\hline 27 & 750 & 4.65 & 30 \\
\hline
\end{tabular}

Calculations of the emission intensity were carried out on the basis of the obtained measurement data in the experiment. They were used to prepare maps of the emission intensity of harmful compounds during the combustion of n-butanol fuel blend. The emission intensity of individual harmful compounds calculated on the basis of equation:

$$
\mathrm{e}_{\mathrm{j}}=\mathrm{u} \cdot \mathrm{c}_{\mathrm{j}} \cdot \dot{\mathrm{m}}_{\mathrm{ex}}
$$

where: $\dot{\mathrm{m}}_{\mathrm{ex}}$ - exhaust mass flow rate, $\mathrm{c}_{\mathrm{j}}$ - concentration of the exhaust component, $\mathrm{u}$-the coefficient depending on the exhaust component.

\section{Results and discussion}

Figure 2 presents a comparison of mass fuel consumption of the engine fed with marine diesel engine and blend n-butanol fuels. One can notice that the fuel consumption are similar for all tested points. In the case of measuring points with lower values engine load, fuel consumption is lower for blended fuel. In the measuring points with higher values of load, the fuel consumption values are slightly higher in relation to the marine diesel fuel (MDF).

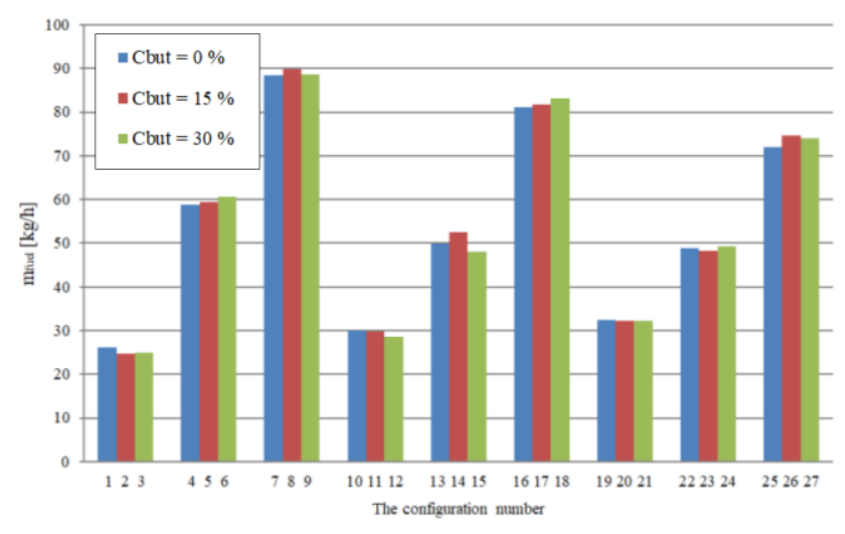

Fig. 2. Comparison of the fuel consumption for the engine fed with blend n-butanol fuel and MDF

Figure 3 shows a comparison of the overall efficiency for engine fed by tested fuels. There is a significant increase in the efficiency values in case of using the n-butanol mixture. It is connected with the oxygen and additional carbon and hydrogen atoms in the fuel chemical compounds. Due to the measuring device used in the experiment, it was not possible to measure the hydrocarbons in the exhaust gas.

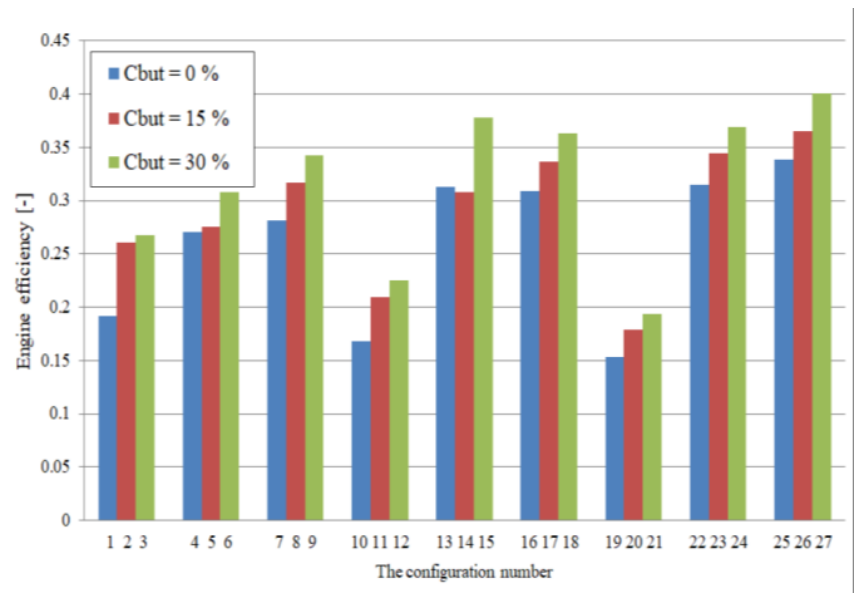

Fig. 3. Comparison of the engine efficiency for the engine fed with blend n-butanol fuel and MDF

Figure 4 presents a comparison the specific $\mathrm{NO}_{\mathrm{x}}$ emission for tested fuels. In general, the blend n-butanol fuels have higher values of specific $\mathrm{NO}_{\mathrm{x}}$ emission compare to marine diesel fuels and the tested $\mathrm{C}_{\mathrm{but}}=15 \%$ n-butanol fuel has the highest values in conducted tests. 


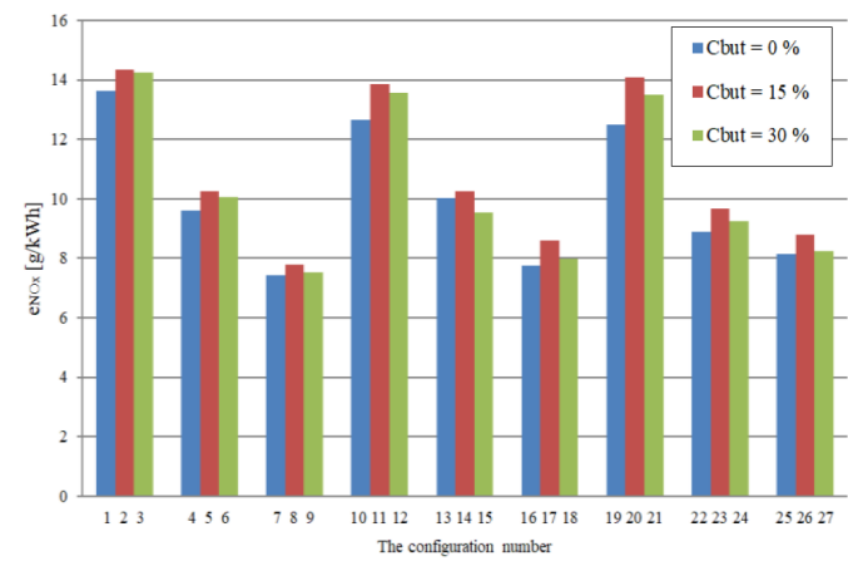

Fig. 4. Comparison of the specific $\mathrm{NO}_{\mathrm{x}}$ emission for the engine fed with blend n-butanol fuel and MDF

Figure 5 presents a comparison the specific $\mathrm{CO}$ emission for the engine fed with tested fuels. Most of the conducted tests show a reduction in the specific emission value in relation to MDF. This demonstrates the improvement of the combustion conditions of blended fuels.

Figure 6 presents a comparison the specific $\mathrm{CO}_{2}$ emission for the engine fed with tested fuels. The values of the specific emission are comparable. However, more accurate calculations show a slight decrease in value relative to the MDF. This is more evident with lower values of rotational speeds and lower values of engine load. The exception are configuration points 25,26 and 27 in which a reduction a value of specific emission was recorded to blend n-butanol fuel.

Figures 7-9 show the surface graph of emission intensity exhaust components: carbon monoxide, carbon dioxide and nitrogen oxides for the tested rotational engine speed $(600,675,750 \mathrm{rpm})$. The graphs were created to illustrate the changes in the intensity of the emission of harmful compounds depending on the $\mathrm{n}$-butanol concentration and the engine load. The matrixes are based on data obtained on the basis of research carried out at the previously mentioned points of the experiment.

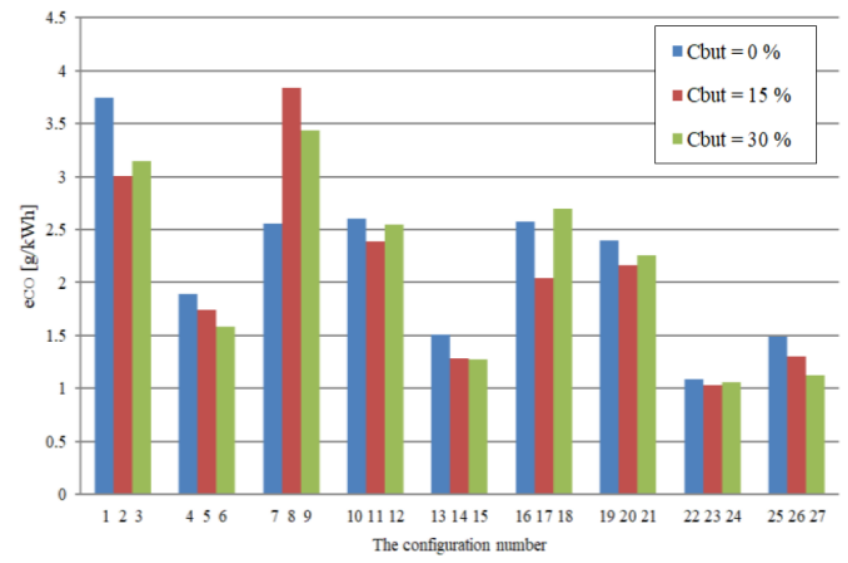

Fig. 5. Comparison of the specific $\mathrm{CO}$ emission for the engine fed with blend n-butanol fuel and MDF

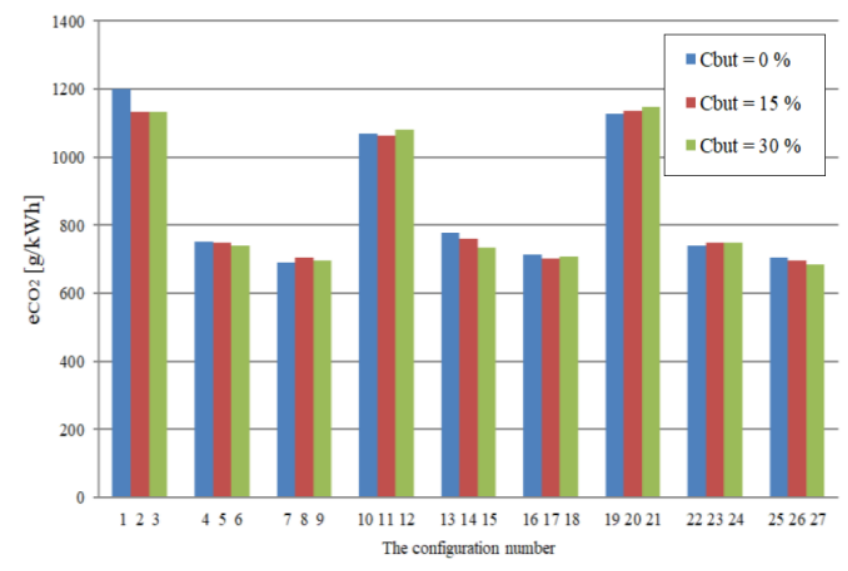

Fig. 6. Comparison of the specific $\mathrm{CO}_{2}$ emission for the engine fed with blended n-butanol fuel and MDF a)

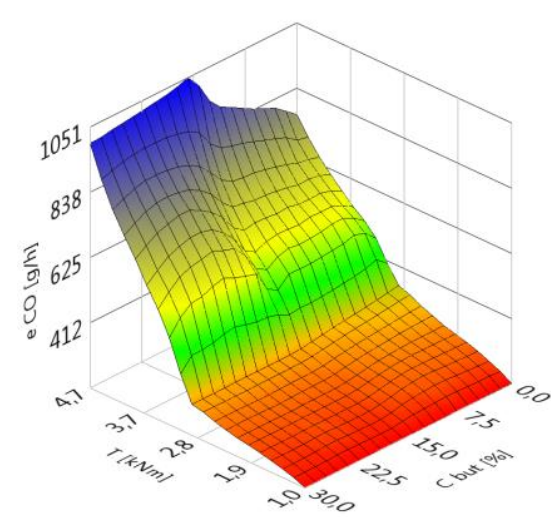

b)

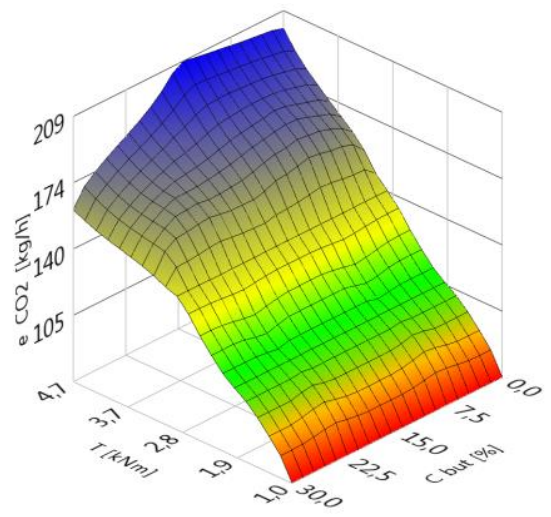

c)

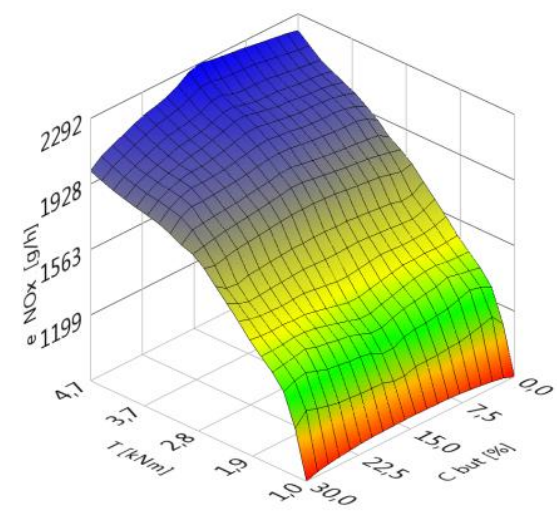

Fig. 7. The surface of emission intensity: a) carbon monoxide, b) carbon dioxide, c) nitrogen oxides at rotation speed $\mathrm{n}=600 \mathrm{rpm}$ 
a)

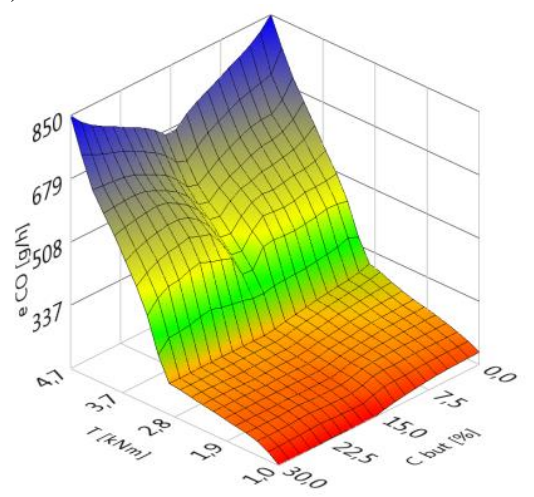

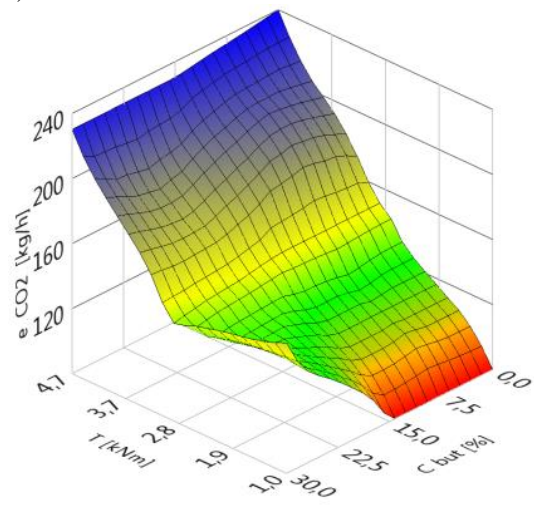

c)

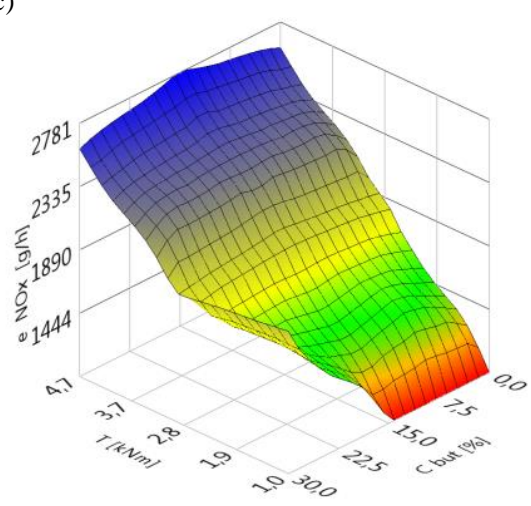

Fig. 8. The surface of emission intensity: a) carbon monoxide, b) carbon dioxide, c) nitrogen oxides at rotation speed $\mathrm{n}=675 \mathrm{rpm}$

a)

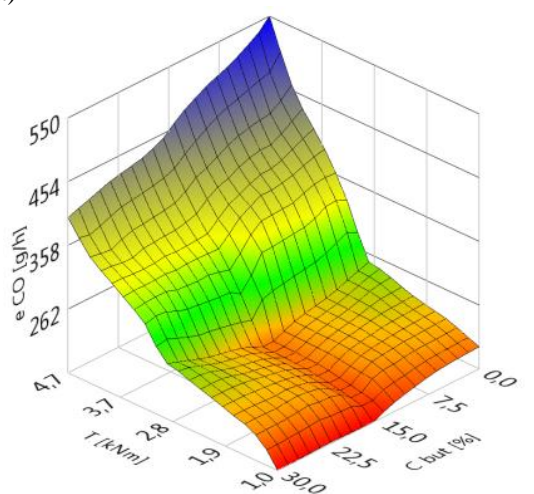

b)

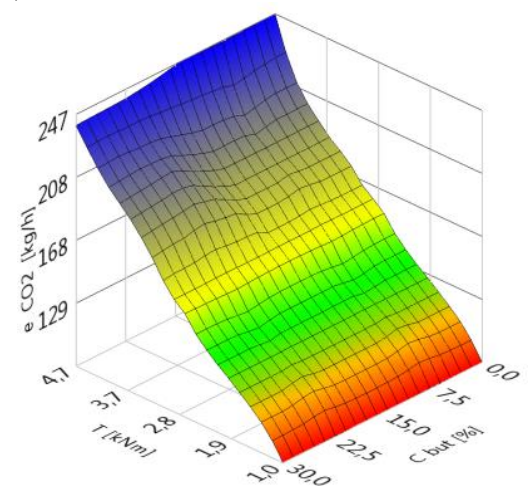

c)

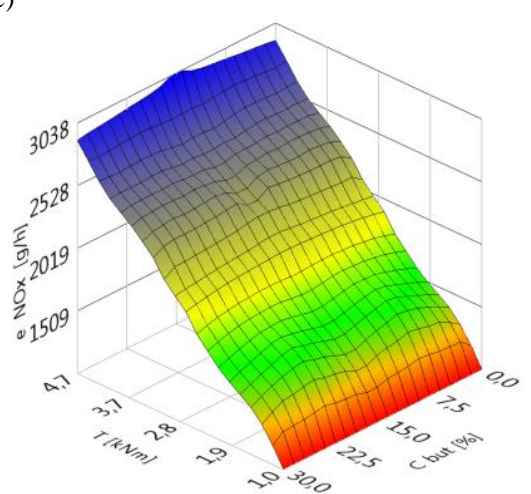

Fig. 9. The surface of emission intensity: a) carbon monoxide, b) carbon dioxide, c) nitrogen oxides at rotation speed $\mathrm{n}=750 \mathrm{rpm}$

\section{Summary}

Research results are satisfactory and will be continued. This is particularly evident in the designated overall engine efficiencies, which have significantly increased. The content of molecular oxygen improved the combustion process in relation to marine diesel fuel. The next tests stages will be supplemented with hydrocarbon concentrations and will cover the remaining area of the load field of the marine diesel engine. The research will focus on issues directly related to the optimal selection of the n-butanol fuel blend. It is planned to conduct optimization process aimed at minimization of emissions harmful compounds from the marine diesel engine relative to then-butanol concentration used in the fuel blend. Based on the emission results it can be concluded, that the blend fuel represents a good fuel alternative for marine fuel in minimalizing greenhouse gases and therefore it should be taken into consideration in the future of marine transport.

\section{Nomenclature}

$\mathrm{CO}$ carbon oxide

$\mathrm{CO}_{2}$ carbon dioxide

GHG greenhouse gas
MDF marine diesel fuel

$\mathrm{NO}_{\mathrm{x}} \quad$ nitrogen oxides

\section{Bibliography}

[1] SEA SHIPPING EMISSIONS 2018: Netherlands Continental Shelf, 12 Mile Zone and Port Areas Sea Shipping Emissions 2018: Netherlands Continental Shelf, 12 Mile Zone and Port Areas Final Report, 2020.

[2] Marine Environment Protection Committee (MEPC 76), 10 to 17 June 2021 (remote session), (n.d.).

https://www.imo.org/en/MediaCentre/MeetingSummaries/P ages/MEPC76meetingsummary.aspx (accessed on 5.07.2021).

[3] IMO update: Marine Environment Protection Committee MEPC 76, (n.d.). https://www.dnv.com/news/imo-update- marine-environment-protection-committee-mepc-76-203128 (accessed on 5.07.2021).

[4] SCHIEL-BENGELSDORF, B., MONTOYA, J.S., LINDER S. et al. Butanol fermentation. Environmental Technology. 34(13-14), 1691-1710, 2013. https://doi.org/10.1080/09593330.2013.827746

[5] JANG, Y.S., MALAVIYA, A., CHO, C. et al. Butanol production from renewable biomass by clostridia. Bioresource Technology. 2012, 123, 653-663.

https://doi.org/10.1016/j.biortech.2012.07.104

[6] LABECKAS, G., SLAVINSKAS, S., RUDNICKI, J. et al. The effect of oxygenated diesel-n-butanol fuel blends on 
combustion, performance, and exhaust emissions of a turbocharged CRDI diesel engine. Polish Maritime Research. 2018, 25, 108-120.

https://doi.org/10.2478/pomr-2018-0013

[7] ZHEN, X., WANG, Y., LIU, D. Bio-butanol as a new generation of clean alternative fuel for SI (spark ignition) and CI (compression ignition) engines. Renewable Energy. 2020, 147(1), 2494-2521.

https://doi.org/10.1016/j.renene.2019.10.119

[8] RYBAK, A., HUNICZ, J., KRZACZEK, P. et al. Effect of different biofuels on common rail injector flow rate. Combustion Engines. 2017, 171(4), 39-43.

Artur Bogdanowicz, DEng. - Faculty of Mechanical and Electrical Engineering, Polish Naval Academy.

e-mail:a.bogdanowicz@amw.gdynia.pl
https://doi.org/10.19206/CE-2017-407

[9] FENKL, M., PECHOUT, M., VOJTISEK, M. N-butanol and isobutanol as alternatives to gasoline: Comparison of port fuel injector characteristics. EPJ Web of Conferences. 2016, 114.

https://doi.org/10.1051/EPJCONF/201611402021

[10] STATSOFT, Statistica - data analysis software system, ver. 6, Tulsa, USA. 2001

Prof. Ryszard Zadrąg, DSc., DEng. - Faculty of Mechanical and Electrical Engineering, Polish Naval Academy.

e-mail: r.zadrag@amw.gdynia.pl

Prof. Tomasz Kniaziewicz, DSc., DEng. - Faculty of Mechanical and Electrical Engineering, Polish Naval Academy.

e-mail: t.kniaziewicz@amw.gdynia.pl 